\title{
Single centre experience of the replacement of ascending aorta with different types of valve-containing conduit
}

\author{
I Andraloits, V Shumavets', A Shket, S Spiridonau, S Kurganovich, L Baraukova, Y Osrtovsky \\ From 23rd World Congress of the World Society of Cardio-Thoracic Surgeons \\ Split, Croatia. 12-15 September 2013
}

\section{Background}

To compare immediate postoperative surgery results in patients after replacement of ascending aorta and aortic valve with various modifications of valve-containing conduit.

\section{Methods}

Replacement of ascending aorta and aortic valve from 2009 till 2013 was performed in 194 patients (18; 9,3\% redo) with pathology of the aortic root. In 19 cases BioValsalva conduit was used $(9,3 \%)$; in 15 pts $(7,7 \%)$ allografts and in $6(3,1 \%)$ stentless bioprosthesis were used with "full-root" technique; vascular graft conduits containing stented bioprosthesis in 16 pts $(8,2 \%)$ or different types of mechanical valve in $139(71,6 \%)$ were used with modification of Bentall procedure. The average age of the patients was $55,7 \pm 12,2$ years, 158 men $(81,4 \%)$. 34 patients $(17,5 \%)$ underwent emergency surgery due to acute dissecting of the thoracic aorta.

\section{Results}

Hemiarch operation were performed in 8 cases, aortic arch complete replacement - in 20 cases; concomitant coronary artery bypass (CABG) - in 33 cases (17\%); concomitant correction on mitral valve - in 34 cases (35\%). In-hospital mortality were $7,8 \%(\mathrm{n}=15,95 \% \mathrm{CI} 5,7 \%-9,1 \%)$ and did not depend on the type of the conduit used. Mortality in emergency and in redo was not significantly higher $12,5 \%$ vs $6,9 \%(\chi 2-1,05, \mathrm{p}=0,2)$.Cross-clamp and $\mathrm{CPB}$ time significantly differed for various types conduits $(p<0,05)$. Frequency of reopen due to postoperative bleeding did not differ between groups averaging $8,2 \%$ $(\mathrm{n}=16, \chi 2-3,31, \mathrm{p}=0,93)$. In the BioValsalva group a smaller prosthesis diameters $(21-23 \mathrm{~mm})$ were used often $(\chi 2-36,79, p=0,012)$. However effective opening area did not significantly differ for different types of conduits with mean iEOA $1 \cdot 2 \pm 0,18 \mathrm{~cm} 2 / \mathrm{m} 2(\mathrm{p}=0,09)$.

\section{Conclusion}

The results show that BioValsalva prostheses are noninferior to other conduits used if choosing smaller valve diameter. Further observation of these patients is required in order to assess long-term results and determining optimum type of valve-containing conduit.

Published: 11 September 2013

doi:10.1186/1749-8090-8-S1-09

Cite this article as: Andraloits et al: Single centre experience of the replacement of ascending aorta with different types of valve-containing conduit. Journal of Cardiothoracic Surgery 2013 8(Suppl 1):09.

\footnotetext{
* Correspondence: vshumaviec@gmail.com

Cardiac Surgery Department, Belarus Cardiology Centre, Minsk, Belarus
} 